\title{
A FILOSOFIA COM CRIANÇAS COMO PRÁTICA PEDAGÓGICA
}

\author{
EMPREENDEDORA
}

\author{
Mauro Sérgio Santos da Silva ${ }^{1}$
}

\begin{abstract}
Resumo: O presente trabalho, realizado através de revisão bibliográfica, visa discorrer acerca da possível relação entre o ensino de filosofia com crianças e a pedagogia empreendedora. Destarte, apresenta os eixos mais importantes da pedagogia empreendedora proposta por Dolabela, define pedagogia empreendedora à luz deste autor e da recepção crítica de sua obra e expõe os elementos centrais da proposta de ensino de filosofia para crianças na perspectiva de Lipman e Kohan. A filosofia para crianças visa à construção de um pensar crítico, criativo, sensível ao contexto e, portanto, capaz de motivar o desenvolvimento de um comportamento inovador.
\end{abstract}

Palavras-Chave: Educação Empreendedora, Filosofia para Crianças.

\section{PHILOSPHY FOR CHILDREN AS AN ENTERPRISING PEDAGOGICAL PRACTICE}

Abstract: This work, carried out through bibliographic review, aims to argue about the possible relationship between teaching philosophy for children and enterprising pedagogy. Thus, it presents the main points of enterprising pedagogy proposed by Dolabela, defines enterprising pedagogy in the light of this author and the critical reception of his work and exposes the central elements of the proposal of teaching philosophy for children in the perspective of Lipman and Kohah. Philosophy for children aims to build a critical creative, context-sensitive thinking, and therefore able to motivate the development of innovative behavior.

Keywords: Enterprising Education, Philosophy for Children.

\section{Introdução}

O presente trabalho tem como mote refletir sobre a possível relação entre o ensino de filosofia para crianças e a pedagogia empreendedora, assim como demonstrar que ensino de filosofia com crianças pode ser considerado uma prática educativa, em aspectos específicos, empreendedora.

A proposta de ensino de filosofia com crianças discutida neste trabalho tem como aporte capitular a análise proposta pelo filósofo educador americano MatthewLipman. E, o

\footnotetext{
${ }^{1}$ Graduado em filosofia pela Pontifícia Universidade Católica de Minas Gerais - PUC/MG. Especialista em Educação Empreendedora pela Universidade de São João Del Rei. Mestrando em filosofia pela Universidade Federal de Uberlândia.
} 
que denominamos pedagogia empreendedora, nessa abordagem, refere-se especificamente ao pensamento de Fernando Dolabela e a recepção crítica de sua obra.

Reconhecendo o inestimável valor da produção intelectual empreendida por Dolabela e Lipman, evidenciando, entretanto, que as respectivas temáticas aqui debatidas merecem novas pesquisas e debates, optou-se metodologicamente pela revisão bibliográfica.

Destarte, na primeira parte, apresentaremos os eixos mais importantes da pedagogia empreendedora proposta por Dolabela (2003) e definiremos pedagogia empreendedora à luz deste autor e interlocutores pesquisadores da supracitada temática.

Em seguida, exporemos alguns elementos da compreensão da proposta de ensino de filosofia para crianças na perspectiva de Lipman (1990) e (1994) e da recepção crítica de sua obra, suas vantagens e pontos de encontro em relação à pedagogia empreendedora.

Apontaremos, nesse sentido, presumíveis aproximações entre uma proposta e outra: elementos conceituais comuns, características das crianças que poderíamos denominar filosóficas e, igualmente, empreendedoras; o pensar, o "filosofar" como "empreender", a filosofia para crianças na escola como prática pedagógica empreendedora.

\section{Desenvolvimento}

\subsection{A filosofia para crianças e a educação empreendedora}

A Unesco (2002) estabelece que a educação deve ser vista como a forma sistêmica por meio da qual os indivíduos sejam capazes de buscar: aprender a ser, aprender a conviver, aprender a fazer, aprender a aprender e, conforme Dolabela (2003), aprender a empreender. Assim sendo, o indivíduo, denominado empreendedor, seria capaz de gerar novos conhecimentos com bases nesses saberes acumulados na sua história de vida. E é isso que conduz ao aprender a empreender, postulado por Dolabela (2003). 
Conforme Dolabela (2003) a pedagogia empreendedora visa à construção de novos valores em uma sociedade heterogênea, marcada positivamente pela diversidade cultural. Mas, entretanto, marcada negativamente pelas diferenças abissais de renda, poder e conhecimento.

Dolabela (2003) parte do pressuposto de que todos nós possuímos originais características empreendedoras. Afirma, outrossim, que nossa educação acaba reprimindo o livre desabrochar e o desenvolvimento de taisatributos. Para este autor, lidar com crianças é lidar com autênticos empreendedores ainda não contaminados pelos valores antiempreendedores da educação, nas relações sociais, no 'figurino cultural' conservador a que somos submetidos.

Nesse processo, a educação filosófica de crianças à maneira proposta por Lipman (1990), especialmente, pode afigurar-se sobremodo relevante. A relação entre a filosofia e o empreendedorismo encontraria terreno fértil na criança e sua original disposição para o novo, para a admiração e o assombro; contribuindo para construção de comportamentos inovadores.

Conforme Lipman (1994) e Kohan (1998), a proposta de ensino de filosofia com crianças possibilita a constituição de um pensar mais criativo, crítico, sensível ao contexto e, destarte, de um comportamento inovador; este último, elemento essencial da pedagogia empreendedora. Isso acontece mediante a transformação da sala de aula em uma "comunidade de investigação", para usar um dos conceitos mais importantes da proposta do educador americano Matthew Lipman (1990), ambiente em que o diálogo não se configura, tão somente em uma estratégia educacional. É, sobretudo: um princípio educativo por meio do qual os alunos são instigados à investigação e à procura, ao pensar livre e à inovação.

A prática da filosofia para as crianças, como estabelece o programa do Centro Brasileira de Filosofia para Crianças (CBFC, 1990) e outras propostas igualmente dignas de 
reconhecimento e respeito parecem acordar em relação a três grandes objetivos: a iniciação filosófica é possível com crianças; a educação para o pensar é possível no interior da escola e; a educação filosófica pode colaborar na preparação para uma cidadania consciente.

Pensar crítica e reflexivamente possibilita à criança o que chamamos de constituição de sentidos desta realidade e de si mesma. E isso é possível pelo diálogo investigativo em uma comunidade que, para esse empreendimento, exige a aprendizagem e a construção de comportamentos, atitudes de cooperação, respeito mútuo, inovação, etc.

Dessa forma, inserida e aplicada no contexto escolar, a prática do ensino de filosofia para crianças se estabelece da maneira mais ampla possível: oportunizando a aprendizagem de conteúdos conceituais, procedimentais e atitudinais por meio do diálogo com os filósofos, com a História da Filosofia e com os textos filosóficos e da disponibilização dos educandos à prática do debate.

Assim, tornar-se-ia possível dizer que as crianças não só estariam aptas à iniciação filosófica, mas sim, possuiriam uma disposição original para uma atitude filosófica na mesma medida em que para o empreendimento. Disposição, esta, amiúde reprimida também pelas instituições de formação ou por valores anti-empreendedores do 'figurino cultural' conservador a que são submetidos.

Portanto, pensamos que a filosofia com crianças, mediante a transformação da sala de aula em uma comunidade de investigação poderia oferecer enorme contributo no intento de manter acesas as centelhas filosófica e empreendedora, frequentemente encontradas entre os mais jovens e encontraria aí um terreno sobremodo fecundo.

Pacheco (2006) aproxima as ideias de Freire e Dolabela. Ao modo como empreendera esta autora, pensamos ser possível estabelecer, outrossim, relação entre o que propõe Dolabela (2003) e Lipman (1990) e, por conseguinte, entre a filosofia para crianças 
e a educação empreendedora. E, ademais, demonstrar como a filosofia com crianças pode ser compreendida como prática pedagógica empreendedora.

Para Dolabela (2003), por exemplo, o conceito de empreendedorismo transcende a questão empresarial e/ou mercadológica e, destarte, não se limita à noção de prática para o enriquecimento pessoal ou vinculada aos interesses do capital. Segundo o criador da pedagogia empreendedora, o empreendedorismo deve amiúde estar ligado à ideia de desenvolvimento social e de inclusão para a construção de melhores condições de vida para o país (DOLABELA, 1999).

A ação empreendedora possibilita às pessoas intervirem, inovando e criando, avançando na busca de novos patamares de produção. A noção de empreendedorismo exposta por Dolabela em sua obra Pedagogia Empreendedora (2003) refere-se à formação de um cidadão atento às mudanças, à busca de oportunidades, e à inovação.

Segundo Dolabela (2003), a pedagogia empreendedora caracteriza-se, sobremodo, por uma abordagem humanista e tem como objetivo capitular a preparação do indivíduo para a construção do desenvolvimento social em virtude da melhoria da vida das pessoas e de superação da exclusão.

Da mesma forma que Lipman(1994) considera que a iniciação filosófica pode ser realizada com crianças, compreende-se, na esteira do pensamento de Dolabela (2003), que a educação empreendedora também pode ser ensinada no ensino fundamental, na educação regular. Além disso, assim como os programas de Filosofia para crianças acreditam que o ensino de filosofia pode contribuir para a construção da prática de uma cidadania consciente, o ensino do empreendedorismo no ensino fundamental está intimamente relacionado a uma educação para a sustentabilidade. 
Pensamos, destarte, que a educação filosófica com crianças, como compreendida por Lipman (1994), pode encontrar-se em consonância com os pressupostos da pedagogia empreendedora proposta por Dolabela (2003).

\subsection{Empreendedorismo: elementos históricos e conceituais}

O empreendedorismo é um processo que se percebe em vários períodos na história da humanidade desde os povos primitivos até os modernos ambientes empresariais e educacionais, provocando mudanças que ocorrem por meio de inovações.

Essa ação contribui significativamente para que a humanidade cresça e descubra sempre algo novo. Nesse sentido, é possível afirmar que a sociedade atual necessita amiúde de pessoas empreendedoras para continuar fazendo descobertas para satisfazer suas necessidades. O que justifica a relevância, a pesquisa e a reflexão acerca de uma educação efetivamente empreendedora. Na perspectiva deste trabalho, algo que pode ser ensinado nas escolas às crianças.

Conforme Tonelli (1997), a expressão empreendedorismo teve sua origem na França, no início do século XVI, para se referir aos homens envolvidos na coordenação de operações militares. Termo que, paulatinamente, passa a ser usado como referência às pessoas que se associavam aos proprietários de terras e trabalhadores assalariados.

No século XVIII, Smith (apud LONGEN, 1997) o conceito empreendedorismo passa a ser associado à figura do proprietário capitalista. Entrementes, o papel do empreendedor pode ser definido sob vários aspectos. Para os economistas, é aquele que providencia recursos, trabalho; que introduz inovações. Para os psicólogos, é uma pessoa dirigida por objetivos muito claros, como a necessidade de experimentar, realizar, alcançar seus ideais. Entretanto, faz-se mister salientar que tal conceito encontra inúmeras variantes quanto à época, autor, cultura, etc, conforme Carmo (2011). 
Segundo Drucker (1987), os empreendedores são eminentemente pessoas que inovam. Postula que a inovação é o instrumento específico dos empreendedores, o meio pelo qual eles exploram a mudança como uma oportunidade para um negócio ou serviço diferente.

Para Fillion (1991) o empreendedor é uma pessoa criativa, marcada pela capacidade de estabelecer e atingir objetivos e que mantém um alto nível de consciência do ambiente em que vive usando-a para detectar oportunidades de inovações.

Porquanto, notamos que a expressão empreendedor, ainda que diante de inúmeras definições, associa-se, amiudei à ideia de inovação. A essência do empreendedorismo estaria, pois, na percepção e no aproveitamento das novas oportunidades no âmbito dos negócios tradicionais, constantemente pensando e criando novas ideias, novos produtos, novos métodos.

Em suma, o empreendedor é aquele que, reflexivamente e sensível ao contexto, percebe a necessidade de realizar, de vencer obstáculos, romper rotinas, definir e alcançar seus objetivos, quebrar paradigmas, pensar e criar o novo. $\mathrm{O}$ empreendedor continua a aprender a respeito de possíveis oportunidades e a tomar decisões moderadamente arriscadas que objetivam a inovação.

Empreender é, pois, a concentração de energia no criar, iniciar e dar continuidade a um empreendimento, uma obra. É o desenvolver de uma organização a partir da observação e análise da mesma. Mas é também a sensibilidade individual para perceber uma oportunidade quando outros enxergam caos, contradição e confusão. É desenvolver competências para descobrir e controlar recursos aplicando-os da forma produtiva (BARRETO, 1998).

Conforme Barreto (2014) o empreendedor pode ser estudado sob diferentes enfoques e por uma variedade de áreas de conhecimento como a psicologia, sociologia, 
pedagogia, economia, administração e outros. Embora nos estudos e pesquisas relacionados com o empreendedor existam muitas diferenças e disparidades a respeito das exatas definições, pode-se perceber que há entre os estudiosos o consenso de que o empreendedor caracteriza-se pela maneira como ele percebe a mudança e lida com as oportunidades de inovação.

\subsection{Empreendedorismo na Educação}

As pessoas são influenciadas desde cedo a se prepararem para um emprego seguro. Porém, no mercado atual, emprego algum é seguro; a manutenção do mesmo depende exclusivamente do desempenho do profissional.

Da educação básica ao ensino superior, pouca ênfase está sendo dada à orientação dos estudantes no sentido de conquistarem autonomia e independência, ou seja, que sejam estimulados ao pensamento reflexivo, autônomo, criativo, livre, sensível ao contexto capaz de gestar comportamentos inovadores; o que requer a utilização de métodos e procedimentos pedagógicos que estimulem o desenvolvimento de habilidades e competências efetivamente empreendedoras nos alunos. Destarte, faz-se necessário que o professor aproxime a realidade educacional e a realidade do aluno: o mercado, a preparação para a vida, para o mundo do trabalho, conforme atual Lei de Diretrizes e Bases da Educação (LDB 9394/96).

A nova proposta educacional, que visa à construção de competências e habilidades, está direcionada para uma aprendizagem em que o "aprender a aprender" e o "aprender a fazer" estejam sempre presentes nas salas de aula. Desta maneira, o educador está contribuindo para que os alunos sejam mais autônomos e desenvolvam a capacidade de avaliar e decidir sobre situações do mundo real (PERRENOUD, 1999). 
O papel das instituições de ensino é proporcionar condições para que seus alunos possam se tornar futuros empreendedores, identificando as visões do que desejam realizar, ou seja, transformar os sonhos em projetos reais (FONSECA Jr, 2014).

Algumas correntes de pensadores acreditam que empreendedores não podem ser formados nas escolas. Seria necessário, antes de tudo, conhecer as características do sujeito, do educando e do profissional que se deseja preparar nas salas de aula e, desta maneira, definir a formação necessária para se chegar ao objetivo intencionado (FRIEDLAENDER e LAPOLLI, 2001).

Faz-se mister constatar que a maioria dos educadores não foi preparada para formar empreendedores, mas sim indivíduos que irão desempenhar papéis definidos há bastante tempo. A modificação das atitudes dos professores ocorre gradualmente à medida que o educador começa a compreender, e vivenciar a conduta empreendedora (FRIEDLAENDER e LAPOLLI, 2001).

Desenvolver empreendedores significa trabalhar atitudes, exercitar o desenvolvimento de conhecimentos atitudinais. Haja vista que o modo de aprender influencia tanto ou mais do que o conteúdo. O modelo de educação tradicional deve adaptarse para formar empreendedores, de maneira que os estudantes não sejam condicionados à passividade, à apatia e à mera reprodução. A sociedade atual requer que os profissionais sejam mais autônomos, criativos, inovadores, obtenham melhor desempenho, sejam competentes nas definições e soluções de problemas, ou seja, exige que este profissional seja um empreendedor (FREIRE, 2002; FRIEDLAENDER e LAPOLLI, 2001).

Em suma, é fundamental despertar a consciência da responsabilidade pelos resultados de tarefas específicas. O conhecimento, entretanto, não se adquire somente em salas de aula, Trata-se de um fenômeno que ocorre diariamente nas diversas experiências e espaços do cotidiano escolar (FRIEDLAENDER, LESZCZYNSKI e LAPOLLI, 2003). 


\subsection{A motivação e o comportamento empreendedor}

O comportamento empreendedor está incluído nas pesquisas realizadas por diversos economistas, behavioristas, psicólogos, psicanalistas, sociólogos. Observa-se nestes, como já mencionado, certa ambiguidade relativa aos conceitos sobre empreendedorismo (FRIEDLAENDER e BRINGHENTI, 2000).

David McClelland foi um dos estudiosos a analisar e discorrer acerca do comportamento do empreendedor. Ele demonstrou que o ser humano é um produto social e tende a reproduzir seus próprios modelos (BRINGHENTI et al, 2000).

O que amiúde percebemos é que a cultura, as necessidades e hábitos de uma região determinam os comportamentos dos sujeitos que a esta pertencem. Assim, normalmente, os empreendedores locais refletem a cultura de suas comunidades. No ambiente globalizado, deve ocorrer mudança no comportamento local, considerando que todas as informações e novidades estarão disponíveis instantaneamente. As atividades profissionais estão sempre ligadas às particularidades locais, porém, as soluções podem surgir de qualquer local.

Especialistas da área comportamental, analisando as formas de pensar, as atitudes e comportamentos que diferenciam os empreendedores, estabelecem suas habilidades e competências.

Destarte, conforme estabelece Pinchot (1985) e Tonelli (1997), assim como todo o ser humano pode ser considerado como possuidor de algumas características que definem sua personalidade, igualmente, no empreendedor, se sobressaem algumas dessas características: a necessidade; a busca frequente por satisfação e pela realização de seu sonho; valores: visão que o empreendedor tem do mundo; conhecimento: visualização do sonho, a intuição; habilidade: facilidade que o empreendedor tem de desenvolver todo o projeto. 
Segundo Maslow (2013) o comportamento humano é motivado pela insatisfação de suas necessidades. Maslow (2013) também afirma que cada indivíduo atualiza-se por si mesmo, buscando seus próprios objetivos e, desta maneira, cada um é capaz de alcançar níveis de satisfação através de uma aprendizagem que acarreta a motivação para o desenvolvimento do indivíduo.

Vários são os conceitos de motivação, mas há relativo consenso de que motivação é um estado interno ou uma condição - descrita como uma necessidade, um desejo ou um querer - que provoca determinados comportamentos do indivíduo e estimula sua persistência. A motivação é importante, pois ela está envolvida em todas as respostas individuais, ou seja, influencia no comportamento humano.

As teorias sobre motivação são muitas, porém todas têm um fundamento básico de que é a satisfação das necessidades que mobiliza o indivíduo. Alberton (2002) postula que a dúvida fica em quanto a motivação pode alterar o comportamento do ser humano, o quanto ele pode ser modificado em razão da motivação. O conceito de comportamento é muito complexo, porém, estudos também demonstram que o meio ambiente, a percepção, a memória, o desenvolvimento cognitivo, o emocional, a personalidade podem ter influência pela motivação.

Deve ficar claro que emoção não é motivação. Emoção é o resultado da interação entre o indivíduo e algum estímulo externo. "Todo comportamento humano tem um motivo, uma causa, uma coerência interna" (ALBERTON, 2002).

A motivação é algo que pertence à esfera da individualidade, depende das experiências de cada pessoa, provoca estímulos diversos que conduzem à superação de desafios. A motivação é primordial para que as pessoas desenvolvam suas tarefas, principalmente na sociedade hodierna, marcada amiúde pela competição. Assim sendo, saber motivar é uma habilidade essencial para um professor. 


\subsection{Educação, motivação e empreendedorismo}

De acordo com Dolabela (2003a), os fundamentos da formação do empreendedor dependem mais de fatores motivadores e habilidades comportamentais do que de um conteúdo meramente técnico. As disciplinas voltadas ao empreendedorismo devem priorizar o comportamento (o ser) em relação ao saber. A proposta não é a transmissão de conhecimentos, mas o esforço no desenvolvimento de características pessoais necessárias ao empreendedor de sucesso.

Conforme BRINGHENTI (1999), a formação do sujeito empreendedor requer habilidades, como o conhecimento e principalmente o comportamento: capacidade de assumir riscos, elevada criatividade, motivação muito grande por resultados, pela autorrealização e busca de comprometimento, dentre outros.

Uma proposta metodológica de ensino empreendedor deve, portanto, contemplar a motivação; o processo visionário; a capacidade de identificação, análise e aproveitamento de oportunidades; a criatividade e o comportamento empreendedor. A abordagem didática deve levar o aluno a enfrentar situações similares àquelas que poderá encontrar na prática. (FRIEDLAENDER e LAPOLLI, 2001).

Segundo Liberato (2004, p. 01)

[...] a escola, espaço de vida, socialização e formação dos jovens, surge neste contexto como Instituição promotora da educação, e, inserida nela, o professor, empreendedor por natureza, e agente determinante na construção dos saberes e das novas competências, cabendo-lhe a missão de preparar esses jovens para uma nova Era, que não é mais a do pleno emprego, e que exige outros referenciais na direção do trabalho e da cidadania.

No texto em questão, Liberato (2004) retoma a proposta do Sistema SEBRAE que, em 1999, iniciou um processo de reposicionamento institucional, quando definiu novas diretrizes para um direcionamento estratégico inovador. Dentre essas diretrizes, uma das 
ações estratégicas prioritárias para a Instituição foi a disseminação da cultura do empreendedorismo e da cooperação em todos os níveis da educação formal e nos diversos meios de comunicação.

Com base no estudo das diversas experiências motivadas e promovidas pela supracitada proposta Liberato postula:

[...] pode-se concluir que as teorias, teses, artigos e resultados de estudos que são realizados em todo o mundo comprovam que a ação empreendedora acontece a partir de três condicionantes motivacionais: uma vontade, uma necessidade e a identificação de uma oportunidade (LIBERATO, 2004, p.08)

No entanto, adverte:

[...] Culturalmente sabe-se que não é fácil mudar um Sistema Educacional tão fortemente arraigado e fragmentado como no Brasil, uma vez que, na cabeça de alguns educadores mal informados e apáticos em relação ao futuro e à realidade atual, o conceito de empreendedorismo ainda pressupõe lucro, dominação capitalista e neo-liberalismo. Porém, concluíse que, quando o jovem é estimulado a pensar e é motivado para uma ação estruturada através de objetivos claros e definidos, os resultados são impressionantes. Com esse olhar empreendedor sobre a educação, pode-se compreender que o empreendedor é aquela pessoa que percebe quem está motivado para fazer alguma coisa (quem tem talento) e motiva para uma ação! Cabe ao educador e a todos os participantes da prazerosa e desafiadora missão de fomentar o empreendedorismo na escola (LIBERATO, 2004, p.10-11)

\section{A filosofia com crianças e o empreendedorismo}

\subsection{A proposta do filósofo educador Matthew Lipman}

Esta parte do presente trabalho pretende aprofundar a importância e a possibilidade do ensino de filosofia com crianças, assim como apontar para a proximidade desta proposta com a pedagogia empreendedora.

Destarte, partiremos da premissa que aponta para a necessidade do exercício do pensamento, para que ocorra enfrentamento das questões envolvidas na busca da construção dos significados que podem resultar no seu próprio aprimoramento e na construção de um 
comportamento efetivamente inovador. E isso ocorre à medida que o exercício do pensar exige a reflexão, a sensibilidade em relação ao contexto, o cuidado, a criticidade e a criatividade.

Muito tem se pensado acerca de alguns aspectos que poderiam, no processo formativo das crianças, contribuir para a formação de um indivíduo mais crítico e criativo no modo como se relaciona com as situações consuetudinárias.

Ante tantas propostas para a educação, interessamo-nos pela tentativa pioneira de Matthew Lipman - um filósofo e educador - também preocupado com o significado da educação, cujo objetivo é o de iniciar as crianças na arte do filosofar, possibilitando-lhes a construção de um pensar mais reflexivo, atento e crítico que as torne aptas para a discussão, a escolha, a tomada de suas próprias decisões e a motivação para um comportamento inovador.

Apoiado em uma vasta argumentação, Kohan (1998) assevera que na obra do filósofo e educador Lipman, a filosofia é apontada recorrentemente como o caminho mais apropriado para uma educação significativa desde a infância. Para compreendermos usa intenção, buscamos descrever, a priori, alguns elementos de sua vida e obra.

Professor Lipman, como é chamado por seus seguidores e colaboradores, nasceu nos Estados Unidos, em 1923. Em 1938, concluiu seus estudos secundários. Todavia, em decorrência de dificuldades financeiras, ingressa no curso de Filosofia da Universidade de Standford em 1945, finalizando sua graduação três anos mais tarde. Doutora-se em Filosofia no ano de 1954, pela Universidade de Colúmbia, em Nova York, seguindo então para a França, onde permanece por aproximadamente dois anos. Regressando aos Estados Unidos assumiu a cadeira de professor de Filosofia na Universidade de Colúmbia (KOHAN, 1998). Mobilizado pela preocupação acerca do ensino de lógica a seus alunos e incentivado também pela solicitação de alguns pais - para que ele, filósofo-educador, desenvolvesse uma 
proposta que pudesse cuidar qualitativamente do desempenho dos alunos - e, finalmente, por acreditar que as crianças podiam aproveitar a educação do raciocínio, contanto que recebessem isso antes em seu desenvolvimento (KOHAN, 1998, p. 22), o professor Lipman cria, ainda em 1969, o primeiro material didático destinado ao programa de Filosofia para Crianças.

Kohan (1998, p. 09) salienta que Matthew Lipman, pioneiro, lança a ideia de que as crianças podem e merecem ter acesso à Filosofia. Não apenas lança uma ideia, mas cria uma instituição e desenvolve materiais e metodologia para que este projeto se materialize.

Dessa forma, ao final da década de 60, o programa de Filosofia para Crianças de Matthew Lipman é concebido, visando uma proposta de educação para o pensar, cujo objetivo é desenvolver dentro do contexto da sala de aula, as habilidades cognitivas, empregando uma metodologia específica para que o aluno possa conseguir pensar no âmbito das ciências e das demais áreas do conhecimento.

Por isso, em consonância com Kohan (1998), afirmamos que as ideias de Matthew Lipman, relativas ao ensino de Filosofia apontam para três aspectos importantes, quais sejam: I) o acesso que a criança deve ter à filosofia desde o ensino fundamental; II) o fato de ser, por intermédio da Filosofia, que a criança possa preservar seu espírito inquisitivo; III) a compreensão de que reflexão filosófica é o recurso privilegiado para o desenvolvimento do pensar bem, ou seja, do desenvolvimento de um pensar crítico, criativo, sensível ao contexto e, portanto, inovador.

\subsection{O exercício do filosofar}

Uma das condições para o exercício filosófico pode ser identificada com a inquietação, que em grande medida depende do fator motivacional, a que nos referimos 
anteriormente. Este, devidamente orientado, conduziria ao bem pensar que possibilitaria a construção de comportamentos inovadores.

O questionamento pode fazer parte do cotidiano da criança. E é justamente por isso que a filosofia com as crianças pode ser compreendida como a oportunidade da passagem do "simples pensar" a um pensar mais crítico, criativo e sensível ao contexto e, destarte, inovador, como requer uma educação empreendedora.

Certamente o processo do pensamento é uma característica inerente ao ser humano, conforme muito bem argumenta Chauí (2000). Porquanto, a autora faz referência a Descartes e à descoberta do cogito. Em seguida, refere-se a Pascal que define o homem como um "caniço pensante". Diante disso, podemos nos perguntar: é realmente possível ensinar alguém a pensar? É bem provável que não, mas é possível ensinar a pensar 'melhor'.

Quando Lipman (1990) aponta para uma educação para o pensar, ele não subestima essa capacidade humana, menos ainda nas crianças. Percebemos que ele faz referência a uma determinada maneira de pensar que difere, qualitativamente, de outra. Sabemos que isso não é o bastante para compreendermos efetivamente a postulação lipmaniana do que é o pensar. Resgatando o significado etimológico desta expressão, faz-se necessário ser radical, ou seja, é preciso ir até a raiz para que a investigação possa contemplar nossa intenção de chegar à essência do que estamos buscando.

Chauí (2000) discorre acerca da etimologia das palavras pensamento e pensar. Ambas são provenientes do verbo latino pendere, que significa ficar em suspenso, estar ou ficar pendente ou pendurado, suspender, pesar, pagar, examinar, avaliar, ponderar, compensar, recompensar e equilibrar.

Chauí (2000) acrescenta: Pensare, que deriva de pendere, caracteriza-se mais como uma atividade sobre ideias, opiniões, juízos e pontos de vista já existentes do que como criação ou produção de uma ideia ou ponto de vista. 
Chauí (2000) observa ainda que os textos de Filosofia, tantos os antigos quanto os modernos - quando escritos em latim - para pronunciar 'pensar', utilizam os verbos cogitare e intelligere. Cogitare que quer dizer "considerar atentamente e meditar", vem do verbo agere, ou seja: "empurrar para diante de si", e também do verbo agitare, que quer dizer "empurrar para frente com força, agitar". Diante disso: "Pensar, enquanto cogitare é colocar diante de si alguma coisa para considerá-la com atenção ou forçar alguma coisa a ficar diante de nós para ser examinada" (CHAUÍ, 2000).

A autora prossegue em sua análise estabelecendo que intelligere constitui-se da conciliação da palavra inter, que significa "entre" e da palavra legere, que significa "colher, reunir, recolher, escolher e ler". Conforme a pensadora brasileira, isto quer dizer "Reunir as letras com os olhos. Neste sentido, intelligere significaria 'escolher entre, reunir entre vários, apanhar, aprender, compreender, ler entre, ler dentro de'. Donde: conhecer e entender" (CHAUÍ, 2000).

Em relação ao conceito de pensar e pensamento, a autora mencionada conclui:

[...] Se reunirmos os vários sentidos dos três verbos - pensare, cogitare e intelligere - veremos que pensar e pensamento sempre significam atividades que exigem atenção: pesar, avaliar, equilibrar, colocar diante de si para considerar, reunir e escolher, colher e recolher. O pensamento é, assim, uma atividade pela qual a consciência ou a inteligência coloca algo diante de si para atentamente considerar, avaliar, pesar, equilibrar, reunir, compreender, escolher, entender e ler por dentro (CHAUÍ, 2000, p. 158).

As palavras de Chauí (2000) a respeito do pensar dispensam comentários. Entretanto, faz-se mister notar que, como atividade atentiva, o pensar precisa ser estimulado (motivado). Isto porque voltamos nossa atenção apenas ao que verdadeiramente nos interessa, ou seja, aquilo que nos significa algo. Dessa forma, para colocarmos algo diante de nós - pensar - é preciso que esse algo nos seja realmente significativo, ao contrário, não lhe prestaremos atenção; enfim, não lhe dispensaremos o nosso pensar. 
Dessa forma, como esperar que os alunos pensem diante de conteúdos escolares que não lhes convidam - estimulam, motivam - a dedicar atenção, por causa do seu [des] significado? Entendemos aqui, o ensinar a pensar proposto no programa de Filosofia para Crianças, como o estímulo (motivação) que propicia ao aluno o interesse pelo significado necessário. Em outros termos, para que o aluno coloque diante de si algo para que possa "considerar, avaliar, compreender e ler por dentro", por ele mesmo, e não para que apenas 'aprenda'.

É possível observar que uma queixa sobremodo recorrente nas escolas - mesmo nos tempos atuais - refere-se à forma como nossas crianças e nossos alunos, de modo geral, pensam. Apesar de entendermos que não se ensina uma pessoa a pensar, dada a condição natural desse processo no ser humano, muitos educadores - em todas as épocas - clamam por alunos que pensem com mais criticidade, criatividade e autonomia.

Neste sentido, afigura-se possível perceber que a compreensão lipmaniana acerca do pensar bem fornece significativas elucidações a respeito desses enunciados sobre o pensar. Isso ocorre na medida em que a proposta do filósofo norte-americano prima por uma educação para o pensar, que se traduz "na consolidação das potencialidades cognitivas das crianças de modo a prepará-las a um pensar mais efetivo" (LIPMAN, 2001, p. 35).

Percebe-se que sua proposta é de uma educação que assegure à criança que já pensa a capacidade de pensar bem, por intermédio de um programa que estimule, motive e possibilite o desenvolvimento do pensamento reflexivo, crítico, criativo e sensível ao contexto e, deste modo, inovador. O que é diferente de ensinar a pensar. Em entrevista concedida ao Centro Brasileiro de Filosofia para Crianças - CBFC, Lipman (1999) argumenta sobre a necessidade de fazer com que as crianças sejam flexíveis no seu conhecimento, nas suas habilidades e nos seus julgamentos, para se tornem capazes de lidar com as diferentes pressões e desafios consuetudinários. 


\subsection{A filosofia para crianças e a "comunidade de investigação"}

A Filosofia, e, principalmente, o seu ensino, vem ganhando notoriedade no cenário dos debates. Sua inclusão no currículo do Ensino Médio (conforme Lei de Diretrizes e Bases da Educação Nacional - LDB 9394/96) e as possibilidades de sua presença, também, no Ensino Fundamental, têm permitido inúmeras discussões sobre tal relevância e quais seriam as finalidades. Filosofia com crianças é uma tarefa que, segundo Lipman (1994), permite transformar a sala de aula em uma "comunidade de investigação", mediante uma perspectiva metodológica que privilegie o diálogo, isto é, a "prática dialógica", através da qual as crianças são convidadas a participar da aula, como afirma Scolnicov:

[...] Crianças precisam do grupo para aprender a externalizar seu pensamento, para aprender o respeito por outros pontos de vista e a importância de critérios públicos de validez. Porém, mais uma vez, uma discussão requer consciência da distinção entre o meu ponto de vista e o do outro ou outros. E é precisamente esta diferenciação do grupo que promove o pensamento. A comunidade pode dar suporte ao pensamento, aguçá-lo, corrigi-lo, mas não é ela que pensa. (SCOLNICOV, 1999, p. 95).

Deve-se perceber que esta prática não visa apenas ser uma troca de opiniões, ou uma simples conversação. É a partir desta prática dialógica presente na "comunidade de investigação" que as crianças exercem, coletivamente, sua busca pelo conhecimento. Sendo assim, Ann Margaret Sharp (2004) em seu artigo "A outra dimensão do pensamento que cuida", defende que a "comunidade de investigação" na sala de aula seria:

[...] um grupo de crianças que investigam juntas sobre questões problemáticas comuns de uma maneira tal que as faz construir ideias a partir das ideias umas das outras, oferecer contraexemplos umas às outras, questionar as inferências umas das outras a gerar visões alternativas e soluções para o problema tratado, além de seguir com a investigação para onde quer que ela leve. Com o tempo, elas passam a se identificar com o trabalho do grupo, ao construírem significados cooperativamente e ao se comprometerem a uma reconstrução em andamento autoconsciente da própria visão de mundo enquanto a investigação procede. Esta construção e reconstrução de visões de mundo é algo coma a qual todos estamos engajados consciente ou inconscientemente (SHARP, 2004, p.121-130). 
O método acima mencionado requer que os professores saibam como conduzir o procedimento, e para isso, afigura-se imprescindível que estejam preparados para uma reflexão com vistas à construção do conhecimento. Desse modo, o papel do professor deve ser o de provocar o diálogo e garantir que sejam seguidos os procedimentos apropriados para a sua realização. Sendo assim, certas "barreiras" entre professores e alunos, e determinadas doutrinas dos profissionais devem ser superadas; elemento igualmente caro à educação empreendedora (DOLABELA, 2003). Nessa perspectiva, o docente terá a função de motivar, estimular os alunos a organizarem e exporem suas ideias e consequentemente fundamentálas.

Desde a filosofia grega o diálogo é pensado como método e perspectiva importante na abordagem dos problemas filosóficos. Contemporaneamente, o diálogo tem sido uma opção para metodologias de ensino - não só na filosofia - utilizada enquanto recurso didáticometodológico. Este instrumento, usado e consagrado por Sócrates com a finalidade de parturiar os conhecimentos de seus interlocutores, objetivando um saber puro e verdadeiro, é também utilizado por muitos filósofos, como exercício que facilita e aproxima do filosofar.

No processo de filosofar com crianças, este princípio fundamental, enquanto método, exerce uma função pedagógica especial. O programa de educação para o pensar, proposto e organizado por Matthew Lipman, privilegiava principalmente as questões filosóficas, pois quando há uma reflexão a partir do diálogo o mesmo pode indicar a constituição de novas descobertas, até então desconhecidas, e consequentemente, há o desenvolvimento da capacidade de pensar, criar, inovar.

Partindo deste princípio, o filosofar com crianças não é ensinar tão somente a História da Filosofia ou a cultura filosófica elaborada durante séculos pelos pensadores. É mediante o diálogo com as crianças que ocorre o que Lipman (1990) denomina possibilidade 
educacional, isto é, a construção de um processo dialógico que problematize o modo como tal saber foi produzido e o relacione com o presente e o futuro das gerações.

Sendo a Filosofia para/com Criança importante para produção de situações de ensino-aprendizagem significativas, muitos têm adotado os pressupostos do pensamento pedagógico-filosófico de Lipman e têm procurado implantá-lo em seus países. Em nosso país, entre os que mais se destacam em aprofundar e apresentar propostas vinculadas à questão da filosofia com crianças no ensino fundamental tem sido o professor da Universidade Estadual do Rio de Janeiro - UERJ, Walter Omar Kohan. Segundo ele,

[...] As regras e os princípios do pensar aparecem sempre ligados a experiências que as crianças estão vivendo: pergunta-se o que significa pensar para em seguida indagar quanto e como se pensa numa escola, para que ir à escola e como deveriam ser as escolas; constatam os preconceitos que habitam no pensar de muitos adultos e então perguntam-se quantos preconceitos existem na sua própria escola; aprendem o valor do diálogo no processo do conhecimento e exigem o diálogo como modo de fazer frente aos problemas que se apresentam na escola e fora dela (KOHAN, 1998, p. 86).

O diálogo elaborado e conduzido na sala de aula com crianças compõe o instrumento elementar da "investigação filosófica". Deve-se ter em vista que esse método, baseado no diálogo, não trata de uma simples confrontação de ideias, ou de uma "roda de conversas", mas trata de realizar um diálogo crítico e contextualizado na tradição a partir da Filosofia, tendo como pressuposto uma reflexão rigorosa que privilegie o afastamento das querelas do senso comum.

As crianças, nas situações do cotidiano, exercem a sua "natureza investigativa", e é certo que deslumbrar-se frente a tais situações pode ser um fator decisivo e importante que as aproxima da filosofia. O diálogo tem para Lipman (1994) a função de motivar a reflexão do mesmo modo que tinha para Platão, sendo assim, o mesmo tem como objetivo motivar a criança a se envolver nas atividades dialógicas, no entanto, é preciso ter em mente que a 
criança precisa ser orientada para a educação dialógica. De acordo com Lipman (1994) as crianças precisam passar:

[...] por um processo de transição em que verbalizam diversos modos de abordar um determinado tópico para preparar o seu maquinário intelectual. Têm que tentar expressar as suas ideias, escutar os comentários, superar a sensação de que o que tem para dizer é absurdo ou irrelevante testando a ideia para aprender com as experiências do grupo e começar a ficar animada à medida que as implicações do tema forem surgindo. Somente ai é que a tarefa proposta, pelo professor, começa a lhe aparecer apaixonante (LIPMAN, 1994, p.45).

De acordo com Kohan (2008) a filosofia contribui significativamente com a formação das crianças, pois ela apresenta um importante fator pedagógico que oportuniza a aprendizagem de uma maneira especial de compreender e elaborar questões filosóficas acerca dos mais diversos saberes. Muito embora o questionamento por si só não tenha garantias que porte valor filosófico, é mediante o exercício do mesmo que se adquire autoconfiança para ousar relacionar as questões e as possíveis soluções passíveis de serem encontradas. Muitas vezes a ausência de questionamento por parte do aluno pode implicar em um modo de ensino que apenas preocupa-se em transmitir o conteúdo, e consequentemente, um tipo de aprendizagem que não se distingue de uma reprodução de conceitos, de definições, de noções, sem efetivamente implicar os alunos no processo de pensar acerca do que já foi produzido por outros. E, deste modo, compromete até mesmo os processos de avaliação que apenas verificam se os conteúdos foram memorizados de forma adequada, ou seja, na avaliação os mesmos são "despejados" para que se possa ter a certeza que o aluno captou o que foi ensinado em sala de aula.

Segundo Lipman (1994) o questionamento dos alunos em sala de aula é de suma relevância, devendo ser proporcionado ao aluno desde as séries iniciais, pois o este se habitua a fazer intervenções e os colegas passam a aceitar a opinião do outro. Para Lipman (1994) o desenvolvimento das habilidades relativas a esta dimensão é mais difícil se proposto apenas 
no Ensino Médio, porque geralmente nesta fase eles apresentam uma condição psicológica e social que os limita muitas vezes a uma exposição frente ao grupo.

Outro fato importante é que na interação pode-se perceber a melhor forma de ensinar, suprindo, assim, as dificuldades encontradas pela turma e, a partir daí, direcionar o seu ensino para facilitar a compreensão. Naturalmente, deve-se levar em consideração o grau de complexidade do que possa ser trabalhado com crianças. Evidentemente um texto que apresente alguma densidade filosófica, por exemplo, pode comprometer o interesse e a motivação da criança. O que? Como? Para quem? São questões que devem ser consideradas desenvolvimento de atividades filosóficas com crianças, para que estas sejam significativas.

Dessa forma, atento a estes aspectos, parece evidente que, entre outros, é através do diálogo que se criam as condições para que a criança desenvolva as habilidades que lhe permitam, dentre outras coisas, formar cidadãos reflexivos, sensíveis ao contexto, críticos (criativos tanto para o mundo quanto para si mesmo) e efetivamente inovadores. Assim sendo, empreendedores.

Destarte, percebemos a importância e a necessidade da implantação do filosofar com crianças a partir do Ensino Fundamental e que tal implementação se coaduna sobremaneira aos propósitos de uma educação empreendedora.

\section{Considerações finais}

Segundo o filósofo grego Aristóteles, a filosofia começa com o assombro, com o espanto diante do mundo, da vida, dos seres, dos fenômenos e das coisas (CHAUÍ, 2000). Sugerimos que a conhecida definição aristotélica indique que a infância, a filosofia e o empreendedorismo possuam uma relação de significativa semelhança, o que sugere a oportunidade e relevância do ensino de ambas nas escolas já nos anos iniciais. Indica, outrossim, que a proposta conhecida como filosofia para crianças do filósofo educador 
MattewLipman situa-se sobremodo próxima à denominada educação empreendedora à maneira como propusera um de seus pensadores mais importantes, Fernando Dolabela.

A infância é uma fase da vida notadamente marcada por descobertas, mudanças, grande abertura para o novo, o diferente e o desafiador. Além disso, as crianças também costumam ter um grau maior de franqueza e de espontaneidade que os adultos.

Todas essas características são igualmente caras à filosofia e ao empreendedorismo. Nesse sentido, parece-nos evidente que a infância é um momento da vida extraordinariamente favorável à iniciação filosófica e à educação empreendedora.

Malgrado, ao menos no âmbito educacional, a infância foi frequentemente mantida longe da iniciação filosófica. Na mesma medida, o empreendedorismo, sob a ótica do capital, parece, ao menos para o senso comum, ser "coisa de adultos" que já possuem "maturidade" para os negócios.

O que acontece com alguma frequência é que as instituições educacionais, em geral, vão ofuscando o brilho filosófico e o espírito empreendedor que existe em nossas crianças, recusando-lhes o direito de questionar, criar e inovar - filosofar e empreender desencorajando-as desta empreitada ou, no mínimo, condenando-as à mediocridade do contentamento de respostas insatisfatórias, em um sistema educacional que privilegia a transmissão de informações, vilipendiando a motivação para o pensar bem, ou seja, o desenvolvimento de um pensamento reflexivo, crítico, criativo, sensível ao contexto. Sugerimos neste trabalho que este pensar bem é um elemento capaz de gerar o comportamento inovador e cidadão.

A filosofia com crianças, mediante a transformação da sala de aula em uma comunidade de investigação, pode ter o atributo de manter acesas as centelhas filosófica e empreendedora, frequentemente encontradas entre os mais jovens e encontraria aí um terreno sobremodo fecundo. 
A ação empreendedora possibilita às pessoas intervirem, inovando, criando e avançando. A noção de empreendedorismo, exposta por Dolabela em sua obra Pedagogia Empreendedora (2003), refere-se à formação de um cidadão atento às mudanças, à busca de oportunidades e à inovação.

Segundo Dolabela (2003), a pedagogia empreendedora caracteriza-se mormente por uma abordagem humanista e tem como objetivo predominante a preparação do indivíduo para a construção do desenvolvimento social em virtude da melhoria da vida das pessoas e a superação da exclusão.

Da mesma forma Lipman $(1990,1994)$ considera que a iniciação filosófica pode ser realizada com crianças e compreende, na esteira do pensamento de Dolabela, que a educação empreendedora também pode ser ensinada no ensino fundamental, na educação regular. Além disso, assim como os programas de Filosofia para crianças acreditam que o ensino de filosofia pode contribuir para a construção da prática de uma cidadania consciente, o ensino do empreendedorismo no ensino fundamental está intimamente relacionado a uma educação para a sustentabilidade.

Pensamos, assim, que a educação filosófica com crianças, como compreendida por Lipman, pode encontrar-se em consonância com os pressupostos da pedagogia empreendedora proposta por Dolabela.

\section{Referências}

ALBERTON, L. Uma contribuição para a formação de auditores independentes na perspectiva comportamental. Tese de Doutorado. . Programa de Pós Graduação em Engenharia de Produção, Universidade Federal de Santa Catarina, Florianópolis, 2002. Disponível<Https://repositorio.ufsc.br/bitstream/handle/123456789/84483/185854.pdf?seq uence $=1$ > Acesso em: 05 de mai de 2014.

BARRETO, L. P. Educação para o Empreendedorismo. Escola de Administração de Empresas da Universidade Católica de Salvador, 1998. 
BARRETO, L.P. Empreendedorismo. Disponível em

$<$ http://pbarreto.com/paginas/empreend1.html>. Acesso em 06 de mai de 2014.

BRASIL, LDB. Lei 9394/96 - Lei de Diretrizes e Bases da Educação Nacional.Disponível em < www.planalto.gov.br >. Acesso em: 25 Jun 2003.

BRINGHENTI, C. Fundamentos para a implantação de pequenas e microempresas de alimentos. Dissertação de mestrado. Programa de Pós Graduação em Engenharia de Produção, Universidade Federal de Santa Catarina, Florianópolis, 2000.

BRINGHENTI et al. Técnicas de ensino do Intraempreendedorismo. Programa de Pós Graduação em Engenharia de Produção, Universidade Federal de Santa Catarina, Florianópolis, 2000.

Empreendedorismo em Organizações. In: ENEMPRE - Encontro Nacional de Empreendedorismo. 1 ${ }^{\circ}$, Anais, Florianópolis: Escola de Novos Empreendedores, 1999. CARMO, Cintia Tavares do. Empreendedorismo. Colatina, CEAD, IFES, 2011. CBFC. Reflexões sobre uma educação para o pensar. Coleção Pensar, Volume III. São Paulo: 1996.

A Filosofia e o incentivo à investigação filosófica. Coleção Pensar, Volume IV.São Paulo: 1997.

Educação para o pensar. Coordenação de Marcos Antônio Lorieri. Direção do Centro Brasileiro de Filosofia para Crianças. São Paulo: CBFC, 1999. 1 fita de vídeo, NTSC, VHS, son., color.

CHAUÍ, M. “Convite à Filosofia”, São Paulo, 2000: Ed. Ática.

DOLABELA, Fernando. Oficina do Empreendedor. 6. ed. São Paulo: Cultura, 1999. Fernando. Pedagogia Empreendedora. São Paulo: Cultura,2003, a. .Fernando. Empreendedorismo: uma forma de ser. Brasília: Aed, 2003, b. .Fernando. Boa Ideia e agora? São Paulo: Cultura, 2000.

DRUCKER, P. Inovação e espírito empreendedor: prática e princípios. São Paulo: Editora Pioneira, 1987.

FILION, L. J. Diferenças entre sistemas gerenciais de empreendedores e operadores de pequenos negócios. RAE - Revista de Administração de Empresas, São Paulo: out/dez, v 39, n 4, 1999.

FREIRE, P. A história de Paulo Freire. Disponível em: <http://www.paulofreire.org/> Acesso em: 10 ago 2001.

.Pedagogia da Autonomia - Saberes necessários à prática educativa. São Paulo: Editora Paz e Terra S. A, 2002. 
FONSECA Jr, R.S. HASHIMOTO, M. A Importância do Ensino Empreendedor na Formação de NívelTécnico. Goiânia, Egepe, 2014.

FRIEDLAENDER, G. M. S; BRINGHENTI, C. e LAPOLLI, E. M. Preparando-se para Empreender. In: ENEMPRE - Encontro Nacional de Empreendedorismo. $4^{\circ}$, Anais, Florianópolis: Escola de Novos Empreendedores, 2002. Disponível em $<$ http://www.dainf.cefetpr.br/ gilda/Downloads\%2020Arquivos/Publicacoes/PREPARAN DOSEPARAEMPREENDER.pdf > Acesso em 05/05/2014.

FRIEDLAENDER, G. M. S e LAPOLLI, E. M. Preparando-se para um ensino empreendedor. In: ENEMPRE - Encontro Nacional de Empreendedorismo. $3^{\circ}$, Anais, Florianópolis: Escola de Novos Empreendedores, 2001.

FRIEDLAENDER, G. M. S. et all. $\mathrm{O}$ ensino do desenho através de experiência empreendedora. In: ENEMPRE - Encontro Nacional de Empreendedorismo. $3^{\circ}$, Anais, Florianópolis: Escola de Novos Empreendedores, 2001.

. O professor empreendedor. In: ENEMPRE - Encontro Nacional de Empreendedorismo. 3으. Anais, Florianópolis: Escola de Novos Empreendedores, 2001.

. Características do Intraempreendedor. In: ENEMPRE - Encontro Nacional de Empreendedorismo. $2^{\circ}$, Anais, Florianópolis: Escola de Novos Empreendedores, 2000.

FRIEDLAENDER, G. M. S. e BRINGHENTI, C. O professor como facilitador do empreendedorismo. Programa de Pós Graduação em Engenharia de Produção da Universidade Federal de Santa Catarina, Florianópolis, 2000. Trabalho de aula.

GUILHON, P. T. e ROCHA, R. A Intrapreneur: multiplicador de novos negócios. Revista Alcance, ano VI, n 1, maio, 1999.

INSTITUTO EUVALDO LODI. Empreendedorismo: ciência, técnica e arte. IEL Nacional, 1999.

KOHAN, Walter Omar. Infância. Entre a Educação e a Filosofia. Belo Horizonte: Autêntica, 2003.

KOHAN, Walter Omar. Infância, estrangeiridade e ignorância. Ensaios de Filosofia e Educação. Belo Horizonte: Autêntica, 2007.

KOHAN, Walter Omar \& WAKSMAN, Vera.Filosofia para crianças na prática escolar. Petrópolis: Vozes, 1998.

KOHAN, Walter Oman\& KENNEDY, David. Filosofia e infância: possibilidades de um encontro. Petrópolis: Vozes, 1999.

KOHAN, Walter Omar \& RIBEIRO, Alvaro. Filosofia na escola pública. Petrópolis: Vozes, 2000. 
LIBERATO, A.C.T. Empreendedorismo na escola pública: despertando competências, promovendo a esperança. Porto Alegre: Sebrae, 2002. Disponível em $<$ http://www.oei.es/etp/empreendedorismo_escola_publica_teixeira.pdf $>$ Acesso em $30 \mathrm{de}$ abril de 2014.

LIPMAN, Matthew; SHARP, Ann Margaret; OSCANYAN, Frederick S. (Orgs). A Filosofia na sala de aula. São Paulo: Nova Alexandria, 1994.

A Filosofia vai à escola. Tradução de Maria Elice de Breezinski e Lúcia Maria Silva Kremer. São Paulo: Summus, 1990. 2001.

O pensar na educação. Trad. Ann Mary Fighera Perpétuo. 3. ed. Petrópolis: Vozes,

LONGEN, M. T. Um modelo comportamental para o estudo do perfil do empreendedor. Dissertação de Mestrado. Programa de Pós Graduação em Engenharia de Produção da Universidade Federal de Santa Catarina, Florianópolis, 1997.

MASLOW, A Maslow's hierarchy of needs. Disponível em:

<http://www.deepermind.com/maslow.htm> Acesso em: 22 set 2013.

PACHECO, Andressa Sasaki Vasques et all. A Pedagogia de Paulo Freire e a Pedagogia Empreendedora. Blumenau, 2006.

PERRENOUD, P. Construir as competências desde a escola. Porto Alegre: Editora Artmed, 1999.

Dez novas competências para ensinar. Porto Alegre: Editora Artmed, 2000. PINCHOTT III, G. Intrapreneuring: por que você não precisa deixar a empresa para tornar-se um empreendedor. São Paulo: Ed. Harbra. 1985.

SCOLNICOV, Samuel. A problemática comunidade de investigação: Sócrates e Kant sobre Lipman e Dewey. KOHAN, Walter O.; LEAL, Bernadina (Orgs.). Filosofia para crianças: em debate. São Paulo: Vozes, 1999. v. IV. p. 89-96. (Filosofia na escola).

SHARP, Ann Margaret. A outra dimensão do pensamento que cuida. KOHAN, Walter O. (Org). Lugares da infância: Filosofia. Rio de Janeiro: DP\&A Editora. 2004. p.121-130.

TONELLI, A Elaboração de um programa de capacitação a partir do estudo das características comportamentais dos empreendedores. Dissertação de Mestrado. Programa de Pós Graduação em Engenharia de Produção da Universidade Federal de Santa Catarina, Florianópolis, 1997.Disponível em<http://www.ead.fea.usp.br/semead/8semead/resultado/trabalhosPDF/381.pdf > Acesso em 05 de mai de 2014.

UNESCO. Organização das Nações Unidas para a Educação, Ciência e a Cultura. Banco Mundial, USAID, Fundação Ford, CONSED, UNDIME, 2002. 